Supporting information for

\title{
Synthesis and mechanical characterization of CuMoTaWV high entropy film by magnetron sputtering
}

\author{
Sajid Alvi ; Dariusz Jarzabek ; Mojtaba Gilzad Kohanc; Daniel Hedman ; Piotr \\ Jenczyk $^{\mathrm{b}}$; Marta Maria Natile ${ }^{\mathrm{e}, \mathrm{f}} ;$ Alberto Vomiero ${ }^{\mathrm{c}}$; Farid Akhtar ${ }^{\mathrm{a}^{*}}$
}

a: Division of Engineering Materials, Luleå University of Technology, Sweden.

b: Department of Mechanics of Materials (ZMM), Institute of Fundamental Technological Research, Polish Academy of Sciences, Warsaw, Poland.

c: Division of Experimental Physics, Luleå University of Technology, Sweden.

d: Division of Applied Physics, Luleå University of Technology, Sweden.

e: CNR-Institute of Condensed Matter Chemistry and Technologies for Energy (ICMATE), Italy.

f: Department of Chemical Sciences, University of Padova, Italy

*: Corresponding author (farid.akhtar@ltu.se)

\section{Spark plasma sintered target}

During the target preparation, we have made sure to perform all the powder preparation in protective argon atmosphere glove box, which is connected to the SPS, where the graphite die was transferred and sintered in high vacuum atmosphere. Furthermore, EDS analysis also showed low amount of oxygen in the cross-section of target, as shown in Table S1.

\begin{tabular}{|l|l|l|l|l|l|l|}
\hline \multicolumn{6}{|c|}{ Table S1: EDS area analysis on cross-section of target in at $\%$ and $\mathrm{wt} \%$. } \\
\hline & $\mathrm{Cu}$ & $\mathrm{Mo}$ & $\mathrm{Ta}$ & $\mathrm{W}$ & $\mathrm{V}$ & $\mathrm{O}$ \\
\hline $\mathrm{at} \%$ & $10.3 \pm 0.9$ & $30.1 \pm 1.0$ & $13.5 \pm 1.5$ & $9.0 \pm 2.0$ & $25.4 \pm 1.8$ & $11.5 \pm 2.7$ \\
\hline $\mathrm{wt} \%$ & $7.2 \pm 0.6$ & $31.7 \pm 2.4$ & $26.7 \pm 1.7$ & $18.0 \pm 2.8$ & $14.2 \pm 1.4$ & $2.0 \pm 0.5$ \\
\hline
\end{tabular}

The EDS mapping of target cross-section in Figure 1b, in the manuscript, does show the inhomogeneous composition, however we have observed a homogenous composition of each elements in all of our film deposition. This homogeneity is related to the formation of high entropy film at the substrate interface. 


\section{Refractory high entropy films}

The surface morphology of film surface from as-deposited and annealed at $300{ }^{\circ} \mathrm{C}$ can be seen in Figure S1. We can clearly observe that there has been no change to the grain morphology and the composition from EDS area analysis in Table S2, which showed similar compositional homogeneity with low amount of oxygen present.



Figure S1: SEM surface morphology of CuMoTaWV high entropy film on steel substrate from a) as-deposited, and b) annealed at $300{ }^{\circ} \mathrm{C}$.

Table S2: EDS area analysis in at $\%$ on surface of film before and after annealing in Figure S1.

\begin{tabular}{|c|l|l|l|l|l|l|}
\hline Spots & $\mathrm{Cu}$ & $\mathrm{Mo}$ & $\mathrm{Ta}$ & $\mathrm{W}$ & $\mathrm{V}$ & $\mathrm{O}$ \\
\hline 1 & $2.75 \pm 0.7$ & $23.8 \pm 0.5$ & $23 \pm 0.8$ & $23.5 \pm 0.7$ & $20.3 \pm 1.2$ & $6.5 \pm 2.5$ \\
\hline 2 & $2.6 \pm 0.1$ & $22.7 \pm 0.3$ & $23.4 \pm 0.7$ & $23.8 \pm 1.2$ & $20.1 \pm 0.2$ & $7.2 \pm 2.0$ \\
\hline
\end{tabular}

Vickers microhardness indentations were carried out at $0.5 \mathrm{kgf}$ on CuMoTaWV high entropy film to investigate the delamination of film to the steel substrate, as shown in Figure S2. The as-deposited and annealed films showed good adhesion to the substrate. However, it can be observed that the as-deposited film on steel substrate showed higher crack opening inside the indent, indicating partial delamination (Figure S2 a-b), whereas annealed film showed insignificant crack opening in the indent (Figure S2 c-d) [1,2]. 

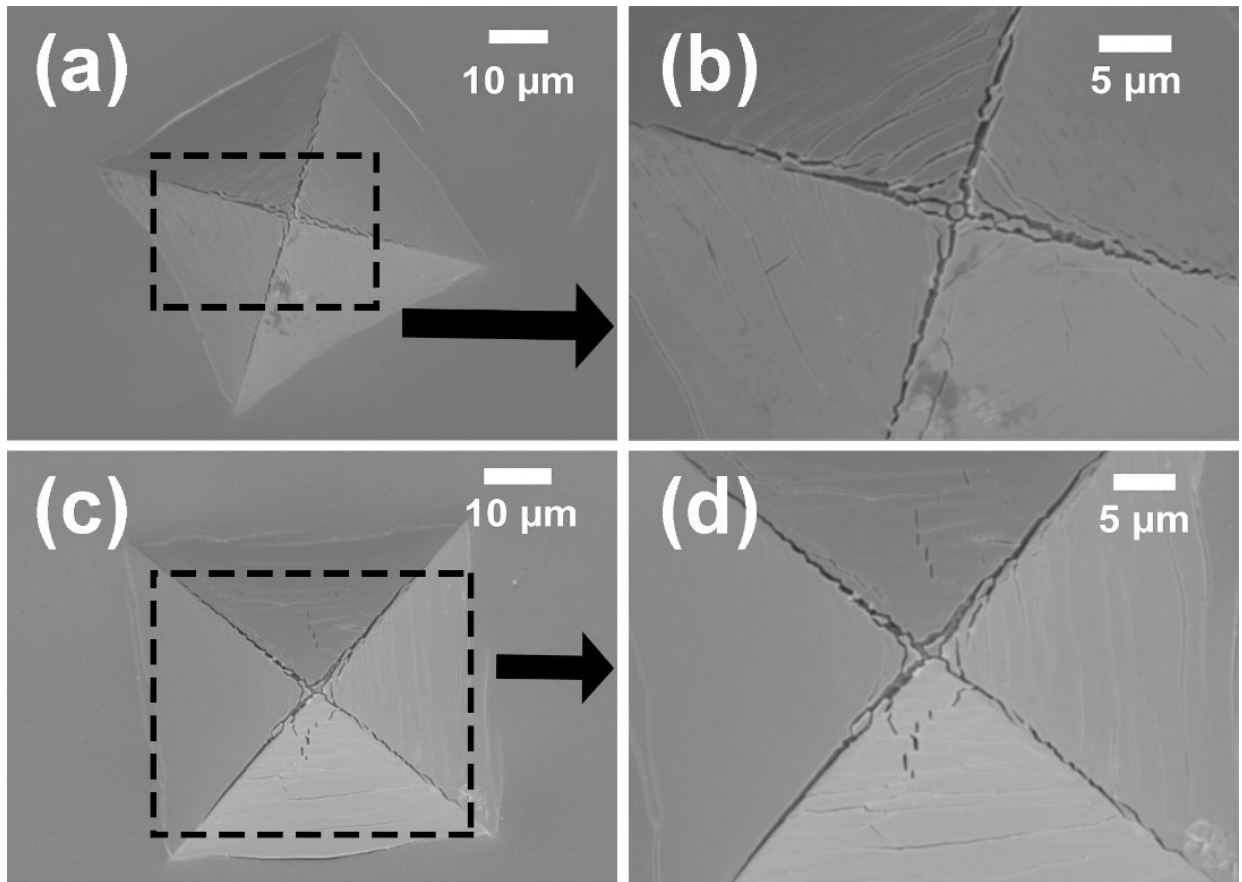

Figure S2: SEM surface morphology of Vickers hardness indents at $0.5 \mathrm{kgf}$ on CuMoTaWV high entropy film from a-b) as-deposited, and c-d) $300{ }^{\circ} \mathrm{C}$ annealed film. 


\section{References:}

[1] S. Zhang, X. Zhang, Toughness evaluation of hard coatings and thin films, Thin Solid Films. 520 (2012) 2375-2389. doi:10.1016/j.tsf.2011.09.036.

[2] M. Betiuk, Evaluation of the PVD and CVD coatings structure using modified method of spherical metallographic microsection (BALTEST-M), in: 13th Int. Conf. Plasma Surf. Eng. Sept. 10-14, 2012, Garmisch-Partenkirchen, Ger., 2012: pp. 455-458. 